\title{
Exploring the Relationship between Homosexuality and Sport among the Teammates of a Small, Midwestern Catholic College Soccer Team
}

Despite decreasing homophobia, openly gay male athletes are still rare in organized, competitive teamsports (Anderson 2005). In this action research, we explore two aspects of homosexuality and sport: 1) the effect of a gay male soccer player coming out to his teammates; and 2) the effect of having an openly gay researcher in the field. This is therefore the first-ever first-hand account of an athlete's coming-out process with researchers in the field. Even though this is action research and therefore not generalisable, we highlight that this research contributes to the body of literature on sexuality and sport because we document the interactions of straight athletes with a gay player and a gay researcher among the heterosexual players at a small, Catholic college in the American Midwest. We use interviews to show that players were accepting of homosexuality before the beginning of this research, and show that discussions with these two gay men further promoted players' perspectives on homosexuality. This led to an increase in the team's social cohesion and a decrease in heteronormativity.

Keywords: coming out, sport, gay athlete, homosexuality, cohesion 
Maintaining a heterosexual identity has been described as being essential for AngloAmerican boys and men (Connell 1987). Constructing this socially-esteemed identity has partially come through the expression of extreme homophobia (Kimmel 1994). This is particularly true of men in contact sports (cf. Messner 1992). Here, men are taught to employ hegemonic oppression in order to improve their position within a rigid social stratification of heteromasculinity (Connell 1987). This has been thought to influence heterosexual male athletes to ostracize, marginalize, and sometimes even commit acts of violence against gay men, and/or those thought to be gay (c.f. Anderson 2000). Sport has therefore served as a socially-esteemed institution where boys formally learn the attitudinal components of hegemonic masculinity, including homophobia. This has made sport a particularly inhospitable social arena for gay male athletes (Pronger 1990).

However, social attitudes toward homosexuality are rapidly changing in U.S. culture (Loftus 2001). This is particularly true among white undergraduate men (Anderson 2009). Despite decades of overt homophobia, contemporary research evidences how more liberal attitudes about homosexuality are increasingly being esteemed in multiple undergraduate settings (Kehler 2007; Taulke-Johnson 2008), something scholars have recently extended into university sport settings (Harris \& Clayton 2007; Price \& Parker 2003; Southall et al. 2009).

Anderson (2000, 2002, 2005, 2009) has examined the experiences of gay male athletes in sport, interviewing over a hundred openly gay high school and university athletes throughout America. However, these accounts have been limited in two ways. First, they have relied solely on self-reports of athletes' experiences of coming out. Second, there is no formal investigation concerning the attitudes of heterosexual 
teammates. This action research helps fills these two gaps in the study of the relationship between gay athletes and teamsports.

Using Anderson’s (2009) inclusive masculinity theory, we highlight that these men came to their current team already demonstrating pro-gay attitudes. However, we find that the openness of one of the researcher's homosexuality and the coming out of one of their valued teammates further promoted acceptance of homosexuality, decreased heteronormativity, and helped improve team cohesion. We attribute this to the sharing of sexual experiences and discussions of homosexuality. Thus, even though these findings are not generalisable, we highlight that they are far removed from the model of homophobic and hyper-macho heteromasculinity that older literature universally attributes to teamsport athletes (c.f. Hekma 1998; Messner 1992; Pronger 1990; Sabo \& Runfola 1980).

\section{Sporting Masculinities}

Indeed, this older literature suggests that contact sports have long been recognized as leading markers of heterosexual masculinity in Anglo-American cultures (Messner \& Sabo 1994; Pronger 1990). From early youth, and throughout young adulthood, boys and men are structured into a desire to be associated with hegemonic dominance by partaking in a sporting culture that shapes identities to align with the culturally dominant masculine form (Whitson 1990).

There is a great deal of sociological literature which shows that heterosexual men come to know the meaning of manhood by defining themselves in opposition to anything associated with femininity or homosexuality (c.f. Britton \& Williams 1995; Burstyn 1999; Burton-Nelson 1994; Messner 1992). According to this literature, competitive 
teamsports are therefore suggested to exist as a microcosm of society's sexual and gendered values, myths and prejudices about the variations in men and women, while also actively constructing men to exhibit, value and reproduce traditional notions of hegemonic masculinity.

Researchers who have examined the issue of gays in sports largely agree that organized sports are a highly homophobic institution (Bryant 2001; Griffin 1998; Hekma 1998; Messner 1992; Pronger 1990; Wolf Wendel, Toma, \& Morphew 2001). Messner (1992: 34) says, “The extent of homophobia in the sports world is staggering. Boys (in sports) learn early that to be gay, to be suspected of being gay, or even to be unable to prove one’s heterosexual status is not acceptable.” And Pronger (1990: 26) states that, "Many of the (gay) men I interviewed said they were uncomfortable with team sports...orthodox masculinity is usually an important subtext if not the leitmotif in team sports.”

However, there are a number of cultural trends related to sexuality and gender that may influence how university-aged men reconstruct their own and other's sexual and gendered identities. The most salient concerns the rapid reduction of cultural homophobia among men of this age group (c.f. Barnett \& Thomson 1996; Loftus 2001; McNair 2002; Weeks 2007; Widmer, Treas, \& Newcomb 1998). This has increased the social legitimacy of alternative categories of sexuality and expands upon the social and political landscapes for gay males - even in sport. Accordingly, there is a rapidly growing body of literature regarding heterosexual men and their increasingly progressive attitudes toward homosexuality in sport (Anderson 2000, 2002, 2005, 2008a, 2008b, 2008c; Harris \& Clayton 2007; Price \& Parker 2003; Southall et al. 2009). In these 
studies, heterosexual male athletes are found to display acceptance toward homosexuality, a central tenet of what Anderson (2009) calls inclusive masculinity.

\section{Inclusive Masculinity Theory and Declining Homohysteria}

Although a number of social factors are influential in re/shaping cultural constructions of idealized heteromasculinity, homophobia is theorized to be the most significant for men (Kimmel 1994; Plummer 1999). Anderson’s (2009) inclusive masculinity theory conceptualizes this through the notion of homohysteria—heterosexual men's fear of being publicly homosexualized through violating rigid boundaries of heteromasculinity. Accordingly, the contextual level of cultural homohysteria is affected by the expression of men's cultural homophobia and femphobia.

Inclusive masculinity theory positions that, in a cultural or organizational moment of high homohysteria, publicly failing to adhere to rigid heteromasculine boundaries homosexualizes men. Homophobia, often used as a weapon of feminizing men (Pharr, 1997), is therefore deployed in order to stratify men in deference to a hegemonic mode of heteromasculine dominance in the same way that Connell (1995) describes.

Homophobic discourse and social stigma are most frequently used to police heteromasculine behaviors in such a culture, but it is occasionally reinforced through violence as well. Thus, as multiple masculinity scholars have shown (Plummer 1999), inclusive masculinity theory suggests that in times of high organizational or cultural homohysteria, boys and men are culturally compelled to express homophobic and sexist attitudes to raise their masculine capital through sporting participation and muscular development, and to raise their heterosexual capital through the sexual objectification of 
women (Anderson 2009).

Important to this research, in such a culture, heterosexual men are also policed to maintain physical and emotional distance from one another (Ibson 2002). In a period of high homohysteria, physical demonstrations of intimacy are generally relegated to playing team sports, with soft tactility (holding hands, softly hugging, caressing, or nonsexual kissing) culturally prohibited. Those who break this script are socially homosexualized and consequently stripped of their publicly perceived heteromasculinity. It is in this institutional context that Kimmel (1994) suggests homophobia is masculinity and it is within this zeitgeist that homoerotic and homosexualizing behaviors can be utilized as effective tools to humiliate and effeminize recruits in hazing rituals.

In a period of intense homohysteria, homoerotic hazing is a valuable tool in organizational cultures, because homosexual acts are considered so despicable that men's willingness to do them signals their devotion to the team. It also implies a willingness to comply with the requests of the senior team members (Anderson 2009).

However, inclusive masculinity theory maintains that as homohysteria declines, the hegemonic archetype of conservative masculinity fails to maintain dominance, and less oppressive masculinities proliferate without social stigma. Men described as ascribing to the tenets of inclusive masculinity demonstrate emotional and physical homosocial proximity and once taboo behaviors lose their homosexualizing significance. Thus, in a culture characterized by inclusive masculinity, heterosexual men are permitted more homosocial tactility (touching) and emotional expressionism (the ability to open up emotionally).

While it is necessary to contextualize research that shows an abatement of 
homophobia in this setting (something we explicate in our results), we must recognize that assessing homophobia (whether high or low levels) is always historically situated, and contextually specific. Indeed, given the changing attitudes toward sexuality in youth cultures more broadly (Lalor \& Rendle-Short 2007; Loftus 2001) we maintain that it is no longer possible to speak abstractly of the level of homophobia in sport-it varies within institutions, and local and global cultures across time.

\section{Theorizing the Influence of Coming Out}

Although decreased homohysteria comes via many media, political, and other influential cultural factors, McCann et al. (2009) suggest that among the numerous ways social attitudes toward homosexuality are enhanced is social contact with sexual minorities. They show that when the homosexuality of a friend is revealed, homophobic men are forced to quickly re-evaluate their impressions of someone they had previously viewed positively. In other words, once they understand that a friend is gay, they experience an "awakening of new ideas" which challenges their preconceptions of homosexuality (McCann et al. 2009, 211). This finding is something that Anderson (2005) retrospectively accounts for concerning gay athletes.

Pettigrew (2008) further identifies the importance of contact in reducing prejudice between heterosexuals and homosexuals. He shows that knowing a gay male helps reduce heterosexual prejudice, but that maintaining the ability to speak to him about sex provides a further reduction in personal homophobia. Thus, in this article we assess how teammates react to an openly gay researcher and the coming out of one of their own players. 


\section{Methods}

This research is part of a larger project examining university men's attitudes toward sexuality in the United States. It is made possible by a grant from the American Institute of Bisexuality.

\section{Action Research}

We take a unique methodological approach in this ethnography. This is not traditional research where variables are controlled for neutrality. Instead, we approached this research from what we call 'an emancipatory framework,' something readers might know as action research (c.f. Coghlan \& Brannick 2000; Greenwood \& Levin 1998; McNiff \& Whitehead 2006; Reason \& Bradbury 2001). Here, we approach our research as a reflective process of addressing social issues, intervening and solving problems, and to develop and change the way members of a group interact.

Our primary aim was to first facilitate the emotional needs of Brent, the gay soccer player. He maintained the right to determine how he wanted to come out, and we shaped our research around his decisions. Our second objective was to measure teammates’ attitudes concerning coming out, and to observe interactions among teammates. Related to this, we also considered how the athletes interacted with the openly gay researcher. We questioned how befriending an openly gay researcher might impact upon their attitudes toward homosexuality, and influence their emotional relationships. Finally, after assessing attitudes toward homosexuality, we desired to know how the outing of a teammate affected the heteronormativity normally attributed to masculinized settings. 
This form of emancipatory research is therefore a form of self-reflective enquiry undertaken by two male researchers (one openly gay and one straight) as we interact with and interview our participants, accounting for our influence in this setting (c.f. Brackenridge 1999). Methodologically, we maintain two goals. The first is to understand our practices, and how they relate to the situations in which the practices are carried out. The second is to bring about social change concerning the relationship between homosexuality and the 21 heterosexual men of this team. As is recognized with this type of action research (Coghlan \& Brannick 2000) we marshal evidence to expose unjust practices (if they exist) and are actively involved in the cause for which the research is conducted—-the betterment of the relationship between sport and gay men. This research, therefore, is as much about pedagogical activism as it is about exploring the influence of social contact with gay men.

\section{Participants}

While looking for American soccer teams to conduct ethnography, we located Brent online. He was a closeted player at a small, Catholic college in the American Midwest. After gaining his interest in researching his team, Brent came out to his coach. After receiving his coach’s strong support (a Catholic Priest) he inquired about the possibility of us study the team.

After ascertaining institutional/ethical permission, we flew to the States. Consistent with our emancipatory approach, we first asked how Brent desired to come out to his teammates. Data collection techniques were then strategized around Brent's 
desires. Thus, the antecedents for this research are not generalisable, but they are nonetheless illuminating.

The players are a fairly homogenous group of heterosexual men, aged 18 to 22 . They hail from middle class backgrounds, and most identify as Catholic through family association. There are also four players of color (three Black and one Hispanic). While most were raised in rural areas, a few come from suburbs.

Situated in the middle of a rural town, the college is described by Brent and his coach as being highly conservative. Highlighting this, athletic administrators feared our study would negatively affect donating alumni. However, these concerns did not result in restrictive sanctions being imposed on our research.

\section{Procedures}

We met the players in a team-meeting. Here, we explained that we were interested in many facets of the relationship between masculinity, heterosexuality, homosexuality and sport. They were also told that one researcher was gay and the other straight. They were told they could opt out of the research, and that while this would not prevent us from socializing and training with them, it would stop us from collecting data on them; but none opted out. After this meeting, both authors joined the team in training, and we began socializing with the players after.

Throughout the course of the 10-days, we socialized, partied, trained, ate, and had multiple conversations with teammates. Although informants were acutely aware of our presence as researchers, we restricted note-taking to immediate recall (Spradley 1970). This enabled conversations to flow smoothly, reducing the obviousness of our roles. 
Notes were coded on revealing an insight into the players' value of homosexuality, and subsequently employed in the results to contextualize their behavioral practices.

Attitudinal data concerning homosexuality and homophobia were first obtained during participant observations and through six formal (30-60 min) interviews before Brent came out. The order of discussion varied, as did the exact wording of the questions, but questions concerned: 1) their views on homosexuality, 2) their social experiences with gay men, 3) difficulties they might have with gay men, and 4) in later interviews, their thoughts about Brent's homosexuality. The amount of time allotted to each question varied depending upon the flow of conversation. Thus, not all questions were asked of each participant.

Finally, most of these interviews were conducted by the heterosexual author, as we thought this might help permit athletes to express more honestly their views on homosexuality. Participants were also told that concealing homophobia would taint our research, and that homophobia expressed to the heterosexual researcher would not be conveyed to the gay researcher until after we had left the setting. All names have been changed.

\section{Coding and Analysis}

This research was approached through an inductive framework with each discursive interaction treated as meaningful and with categories emerging through on-going analysis (Oberhuber \& Krzyzanowski 2008). It is our perception that having two researchers in the field not only facilitated a broader and deeper collection of data, but it also strengthened the thematic coding and analysis of events (cf. May \& Pattillo-McCoy 
2000). We met for data collaboration and interpretation sessions several times daily. Here, we discussed our joint and independent observations, frequently interrogating each other's interpretations. We maintain this dual-author approach provides a more thorough and valid investigation of the multiple meanings and interpretations of the social events among members of this team.

The resulting 'mediated-data' was re-coded after completion of data collection. This permitted a cross-checking of how data was interpreted. Next, all the mediated research notes were cross-verified with the second author, in order to maximize validity and reliability of data. Thus, two approaches to coding are utilized in this research: one during the data collection phase (making initial interpretations of original field notes, resulting in mediated data), and one after the data collection phase (cross-checking original field notes with mediated data to see if interpretations had changed).

\section{Researcher Effect}

We were accepted into the team for several reasons. The gay author's expertise with sport psychology, his openness to discuss homosexuality, and his athletic ability gave him capital. Moreover, the primary author is a semi-professional soccer player in the UK. Thus, our familiarity with sport made us more aware of the local uses and meanings of "shop talk," giving us the ability to engage in this specialized dialogue and to better blend in with athletes during social situations. This helped us gain intimate access to otherwise closed social spaces (dorm rooms, parties, and locker-rooms). Our openness to discuss sexual issues also permitted more meaningful discussions (reciprocation), increasing research validity (Davies 1999). However, we recognize that we also remained outsiders 
in this project. Our age difference, the homosexuality of one of the authors, and our status as researchers are marks of outsiders.

We are also aware that the homosexuality of the second author, the pro-gay attitudes of the players' coach, and the pro-gay attitudes of the first author likely influenced the research findings in multiple ways—particularly in relation to participants' views on homosexuality. We acknowledge this researcher effect, and attempt to outline the nuances of our influence on our informants.

\section{Interviews before Brent Came out}

The heterosexual author interviewed six men before Brent came out. When discussing homosexuality (among other topics), three of the men thought all of their teammates would accept a gay athlete, while the other three suggested a gay athlete might not be accepted by all members of the team. None could, however, name any player they specifically thought might have difficulty with a gay teammate. Furthermore, none maintained that they would have difficulty with a gay teammate themselves.

Although two said showering situations might be awkward, they did not consider this particularly troubling. Tom said, "It might be strange in the locker room, but I think you'd get used to it pretty quick.” Jason added, “Like anything new, it would definitely throw you off a little. Maybe some people would struggle with it more than others. But we all adapt, that's part of being a team.” Howie agreed, “It might be a little awkward at first, but I'd get over it.”

None of these six players said they would blame a gay teammate for making them

feel awkward. Instead, they suggested that they would need to overcome their personal 
discomfort. Tom said, “.... Besides if he’s been closeted, he may have been checking us out already.” Mark added:

I can say to you as much as I want that it wouldn't bother me one bit, and it wouldn't in the sense that I'm not at all homophobic, but I've never had that situation...so I know it would be on my mind. But it would just be something that I, personally, had to get over.

Finally, these six athletes also postulated that an openly-gay player would not negatively impact upon the team's level of cohesion. "No,” Tom speculated, “Why would it lower morale? A friend is a friend, regardless of his sexuality.”

However, none of this inclusivity stemmed from suspicion that there was a gay player on the team. During the first two days of observations, none asked us if Brent was gay. In fact, on the second night, we were sitting around a board game with eight players. Max, a freshman, was asking Brent about his trip to Amsterdam. "Did you pay for pussy?” he asked, referencing the legal trade of heterosexual prostitution in Amsterdam. Brent simply answered, "No.”

Brent said that this is how he normally manages his sexuality. He offers short, direct answers without giving away his sexuality. It is a tactic which permits him to be heterosexualized by the heteronomative standards of his teammates. By all accounts, Brent's strategy worked, players were surprised to learn he was gay. 


\section{Outing Brent}

Brent determined that he would prefer to out himself to several of the seniors first, and that we should out him to the others. Thus, Brent outed himself to a number of close teammates on the third day of our research. He received favorable responses from all. For the younger players, we determined that it would be best for the heterosexual researcher to out Brent (to reduce researcher effect). Later, the gay researcher outed Brent to others.

While talking about homosexuality with Ben, the heterosexual author asked, “How do you feel about the fact that Brent is gay?” Ben responded, “Brent is gay? You serious [sic]?” After receiving confirmation, Ben said, “That’s cool. I just had no idea, that's all.” And when talking in Tom's room that same night, the same question evoked, "What? Brent's gay?... That's fucking awesome."

The gay author outed Brent to Max. Referring to the discussion about Amsterdam he said, "I thought it was funny you asked a gay guy if he paid for 'pussy.' "Wait, you're saying Brent is gay?” Max asked. “Yeah,” the author answered. “Oh. I didn’t know that. Well, shit, I feel bad now.” Max clarified, “It’s no big deal. I just didn’t know.”

Although Anderson (2009) finds highly inclusive attitudes among teamsport athletes in other research locations, we thought these attitudes were a particularly interesting finding. This is because these men represent a demographic of Midwestern rural youth who have been socialized into a Catholic ethos. But despite this, Brent could not recall his teammates ever intellectualizing homophobia. He had not heard homophobia intellectualized. Brent’s coach confirmed, “I’m very close to my players. They often come to my house for dinner. I can't think of anyone on this team who has expressed homophobia.” 
It therefore appears that the acceptance of homosexuality we document is less attributable to researcher effect and more accurately reflects a majority position of positive attitudes toward gay men before we came to the team. In order to examine for this, we inquired about exposure and attitudes toward homosexuality in the interviews of remaining players.

All but three of the men knew a gay male before the commencement of this research. Most maintained informal relationships with gay men, but some had strong friendships, too. The common narrative was that most had a friend or family member who is gay, and they used this association to express a learned degree of social inclusion. Men talked about gay uncles, friends, neighbours, etc. While most reported never being homophobic, a few expressed that they learned to work through homophobia after meeting a gay man. What these men had not known, however, was a gay male teammate.

\section{The Influence of Open Communication}

Teammates often live within what Anderson $(2009,56)$ calls a "near-total institution." They train together, live together, travel together, and party together. Accordingly, athletes can grow emotionally close. Thus, men on this team felt free to discuss homosexuality (in-depth) with Brent. John said:

I've known gay guys, yeah; but Brent is the first one that's part of my core of friends...we spend lots of time talking about all types of deep or personal things... and now I can ask him stuff I've never been able to ask other gay guys. Steve states matters more bluntly: 
I've always wondered whether it feels good to be fucked. I asked, and now I know. I asked Brent all kinds of stuff about gay sex. It’s cool, it’s totally different than what you'd talk to your straight friends about; but then again it's really not different.

While most of the 22 heterosexual men had some previous contact with gay men (and while their coach is a pro-gay Catholic priest), most players have not had the opportunity to ask detailed questions about homosexuality. Tim said, "My uncle is gay, yes. But you can’t just talk to your uncle about what anal sex feels like, can you?” This highlights the pedagogical activism of the study. We spent dozens of hours talking about homosexuality with these players. Over conversations on runs, at dinners, or while hanging out in players houses, the gay author answered questions about his homosexuality. These conversations seemed to endear the author to the players. And this leads us to suggest that there is a difference between the most salient and the most significant finding of this research.

Perhaps the most salient research finding is that this group of men who might traditionally be described as having conservative sexuality beliefs (because of their Catholic and teamsport affiliation), appear to have come to a place of relative social inclusivity for gay men before our ethnography. Part of this is attributable to a distancing from Catholicism. Many suggest that they lost their homophobia when they began to disassociate from religion, signaling that a cultural inertia exists to liberalize the more conservative sexual and gendered perspectives of their parents. Tom said, "I gave up religion.” Mark said, “I believe in god but don’t use religion or the bible to make decisions.” John adds: 
My dad is a big-time homophobe. He sometimes pretends it's not to do with religion, but I have a hard time believing that. He’s anti-gay marriage and anti-gays in general. I believe in God too, but we're totally different on our thoughts on those issues.

Nick says he is only Catholic by culture:

My parents are devout Catholics, so I was raised Catholic. I still say I'm Catholic when people ask, and I wear a cross, but I actually stopped going to Church about two years ago. It's not something I use to guide my moral judgments.

Mark suggests that his dad's homophobia drove him away from religion:

When we [Mark and his brother] were about twelve years old, my dad [highly religious] stopped us having sleepovers with guys, because he thought it might turn us gay. I thought that was just stupid, and thought that any religion which hated people for being gay was pretty fucked up.

However, the most significant of our findings, is that openly discussing the particulars of homosexual sex seems to further upgrade emotional feelings about homosexuality.

Howie said, "When [second author] said he was gay, we were like, alright, whatever, that's cool. I think we talked about it [homosexuality] more those few days because [second author] was around. And then Brent came out, so now it's here on our doorstep.” Howie added, “And now we've had even more chances to talk about homosexuality with gay men, so I think people are just even more comfortable with it.” Ed said, “I wasn’t homophobic before I knew Brent was gay. But knowing him has made me pretty positive about gay stuff.” And when Ed is asked how knowing Brent is gay has specifically facilitated this, he answered: 
We've spent the last few nights just lying on the couch talking about sex and about what it was like being closeted...I've grown to understand things from his [homosexual] perspective....Hell, I can even tell you what kind of guys he’s attracted to now. I think the more you understand something, the more you accept it.

Also reflecting on his new-found sensitivity to Brent's homosexuality, Scott said, "We were walking between classes yesterday and I just knew Brent was checking out a guy, and I just said 'Yep, I saw him, too.'”

David is another player that is close to Brent. When asked about how his friendship with Brent has been influenced by his coming out, he said, "Yeah, Brent is great. I mean, you can talk to him about anything, and I learned a lot about homosexuality from him already. I think his coming out has really bonded us. We're great friends.” Mike added: We've both been here for four years, and I've always considered him a good friend. Things are the same as they were before I found out that he was gay, but now he can be more honest. I think that's real cool.

Mike also suggested that his perspectives on sexuality have evolved during the research period. "Talking with you [gay author] about this stuff has been awesome. I never really had anyone to talk to about that kind of stuff before.” And when asked if talking about homosexuality has made him feel more endeared to Brent, he said, “Absolutely, it’s like he's told us this, and he didn’t have to. I just love him even more now.”

Similarly, Jason recognizes the potential influence that social contact with both homosexual men and pro-gay men can have, not only in reducing prejudice, but in further facilitating their existing tolerance and acceptance of homosexuality: 
I think people would be more open to homosexuality if they were around it more. It would open their eyes; make people a little more open to the possibilities...I mean, most of the guys here [on the team] knew gay people before they came here [to college], so we are pretty cool with it....but now Brent is gay, I mean now we know he’s gay and we know him personally and stuff, and this whole thing [the research] has brought that to our attention. I think it’s opened up our eyes to new levels of openness beyond how open we thought we were.

Danny added:

I wanted to know what he [Brent] thought, being gay and all. Maybe I'm ignorant, but I asked him if it was a choice, not that that was what I believed. I just wanted to hear it from him, so I spoke to him about it a little bit. He said he knew from a young age and that he didn't just turn gay. It's not conclusive, but when you hear it from a gay guy directly it's gotta tell you something.

It is also significant that these men often ended discussions about the origins of homosexuality with a statement of indifference. We often heard them remark that "it makes no difference." One said, "I wouldn't treat him differently," and another asked, “Does it matter?”

Trent said:

It didn't matter to me if someone was gay before I met you guys; people are what they are. But I guess Brent is the first gay guy who I would call a true friend, and talking with you guys about this stuff has really been cool. I understand things so much better now. I feel like I can tell you guys anything. 
Thus, having Brent come out publicly (combined with having an openly gay researcher in the field), provided these players with the opportunity to partake in sexualized conversations: The type of conversations they have not been able to have in an ostensibly heterosexual, homosocial environment. The event of Brent's coming out to the team encouraged teammates to talk about their own sexual and gendered experiences, and their social experiences of other gay men they had previously met.

\section{Challenging Don't Ask, Don't Tell}

In addition to finding that these participants maintained pro-gay attitudes prior to our arrival, and in addition to finding that discussing homosexuality with gay men further enlightened their views on homosexuality; once Brent came out to his teammates there was an immediate change to the once heteronormative discourse used by the team.

Previous research on gay male athletes shows that about half of gay athletes exist within a don't ask, don't tell culture (Anderson 2005). Here, gay athletes and their teammates silently agree upon a culture in which none speak of the gay player's sexuality. Inclusive language is therefore not part of the team's communication style. However, coming out publicly, and discussing homosexuality openly, seems to have warded off a don't ask, don't tell policy with this team.

Exemplifying the efforts of these players to discursively integrate Brent's sexuality into their conversations, while driving home from a match Drew talks about how he thought a few of the female soccer players, who played on the field adjacent to them, were attractive. He immediately follows with, "Did you find any of the guys hot, Brent?” Brent answers, “Yeah, a few.” Drew replied, “I thought number nine was hot.” 
Another time the men determined they should not go to the normal dance club they frequent, because there was no gay club in the same locale for Brent. Instead, we drove to a different venue, so that Brent, the authors, and a few of the players could patronize a gay club. Furthermore, when players were asked if they would support Brent's (theoretically) bringing a boyfriend to a match, none voiced concern. Conversely, at one of the three games we observed, players introduced their parents, inculcating homosexuality in an inclusive manner: “This is [authors’ names], and they’re doing a study on Brent's coming out.”

\section{Leaving the Players}

On the final night of our research, several of the players organized a party. It served to celebrate Brent's coming out; to celebrate the fact that the team had advanced to a higher level of competition than ever before; and it was also a way to say goodbye to us, the researchers. Throughout the course of this evening, players expressed their gratitude that we came to help Brent come out. They also expressed that we had helped them feel more cohesive, as a team.

Mark said, “I feel so much closer, not only to him, but the other guys now, too. It's like we can talk about anything.” Javier added, “I'm just glad for him that he doesn't have that pressure of hiding it anymore... I think it's cool that he's open to me asking him about it.” Tom said, “I feel like a wall has been broken since Brent came out, we’ve been talking about all kinds of things. I just feel so much closer to these guys now.”

Brent’s coming out, and discussing issues that are socially coded as ‘taboo’ and/or 'private,' seems to have reinforced the inclusivity of men on this team and helped 
promote social cohesion among teammates. This is in sharp contrast to the myths reported by many in sports media, that suggest that a player's coming out would harm a team’s cohesion (c.f. Nylund 2007).

Highlighting the socio-positive influence that Brent's coming out had among the men of this team, in a lengthy 'thank you' card to us, his Coach wrote “...my team is stronger, closer, and better than they were before you guys came. More important, they are even more compassionate and caring people because of your visit.” This highlights the pedagogical affect of our research.

In a follow up interview, Brent said that although he feared coming out, it had the opposite effect:

I was not shunned by my team...I was accepted for who I am, and I am much closer with many of my teammates for it. The way things are now, makes me wish that I did it much sooner. It has opened me up and given me a chance to be and do things that truly make me happy.

\section{Discussion}

Sport is widely recognized as a highly homophobic institution (c.f. Pronger 1990). The marginalization of gay athletes has largely been achieved through cultural narratives emphasizing a vehement rejection of homosexuality and the silencing of gay identities through the prolific use of homophobic discourse. However, this social landscape is rapidly changing. Our findings support multiple, recent, ethnographic investigations that show more progressive attitudes in sport today (Anderson 2000, 2002, 2005, 2008a, 2008b, 2008c; 2009; Harris \& Clayton 2007). Thus, despite decades of overt 
homophobia, our findings contribute to a body of literature indicating a growing climate of tolerance, acceptance, and inclusivity for homosexuality.

In this research, we analyzed the outing of a teammate alongside the researchers' pedagogical efforts in a teamsport environment, at a small, conservative, Catholic college in the American Midwest. It is the first-ever account of outing a teammate with researchers in the field.

We suggest that social contact with gay men (whether through prior contact, Brent, or the gay author) provided these men with a forum which contributed to upgrading their intellectual and emotional attitudes toward homosexuality. The finding of importance is that, regardless of who told the 21 heterosexual men on this team, none reacted with, rationalized, or accepted homophobia. In the moment of realization, none of the athletes spoke in rejecting ways about Brent's homosexuality. Although a few expressed that they wished Brent had come out earlier, none felt that his outing was inappropriate. Interestingly, none thought that this would reduce team morale either.

While some players may have engaged in impression management (we cannot be sure that our participants did not censor their words), it is equally possible that team members positively reflected on homosexuality through learning that one of the researchers was gay. This may have promoted a gay positive sensibility that would not exist if both of the researchers were straight. However, the heterosexual author examined for this by conducting four formal follow-up interviews six months after we left. Here the players again represented their support for homosexuality, and none felt that any of their teammates were hiding homophobia in our presence. 
Another significant finding is that when Brent came out (or was outed) to his teammates, it resulted in players feeling closer to him. This was particularly true when openly discussing homosexuality. We suggest that, through their exposure to a gay teammate (and a gay researcher), these men were provided with greater access to the narratives of sexual and gendered 'others,' and increasing opportunities for selfdisclosure. This seems to have the effect of influencing these particular heterosexual men to further promote their emotional and intellectual inclusivity of gay men.

Furthermore, previous (non-sporting) research shows that when a friend comes out as gay, it challenges preconceptions heterosexuals may have of gay men and forces them to re-evaluate their friendship with gay men. Or, as McCann et al. $(2009,211)$ say, they often experience 'an awakening.' In this moment, knowing a person and then finding out he is gay means one's acceptance of that gay person is influenced by knowing him to be a good friend, first. This is how we interpret what we saw occurring in this setting.

We also found that the teammates’ positive evaluation of Brent is influenced by their previous social contact with gay men. We found players had 'awakenings' about homosexuality before we arrived. Therefore, even though we came to this location to do action research (and still did) we found that most of the players came to this team already inclusive of homosexuality. The coming out of one of their friends (as well as meeting a gay researcher) simply provided further exposure, which seems to have further improved their attitudes toward homosexuality.

Observations of player behaviors also suggest that when Brent came out it helped erode at a culture of heteronormativity. In this case, it occurred through 
discussing aspects of Brent's personal and sexual life. Athletes acknowledged that multiple sexualities exist, and this was manifest in subtle adjustments in their language. All of this is consistent with inclusive masculinity theory.

Finally, contrary to media-driven myths about players coming out, in this case, the effect of social contact with a gay teammate had a positive, if nuanced, effect on their social cohesion. In this, the first-ever research concerning the experience of the teammates of an openly gay athlete who comes out to his team, this seems to be confirmed. Brent, his coach, and the overwhelming majority of the heterosexual men studied, all support this hypothesis—coming out did not lower team morale.

What we cannot answer with this research, however, is how a player's homosexuality might affect his team standing and interpersonal relationships with a homophobic individual. Thus, we stress that coming out is not necessarily going to be judged as a positive event for all athletes.

Still, in this research, we showed that there are multiple levels of social analysis that influence the pro-gay attitudes of players on this team. Early contact with gay men, combined with a culture of decreased homophobia; the influence of a teammate's coming out; the activist work of their coach; and the opportunity to discuss homosexual sex with sexuality researchers, all combined to have an influence of upgrading emotional and intellectual perspectives on homosexuality. These men therefore exhibited attitudes toward homosexuality that are far-removed from the homophobic model of masculinity normally attributed to teamsport athletes. 


\section{References}

Anderson, E. (2000) Trailblazing: America's first openly gay high school coach (Fountain Valley, CA, Identity Press).

Anderson, E. (2002) Openly gay athletes: Contesting hegemonic masculinity in a homophobic environment, Gender \& Society, 16(6), 860-877.

Anderson, E. (2005) In the game: Gay athletes and the cult of masculinity (Albany, NY, State University of New York Press).

Anderson, E. (2008a) Inclusive masculinities in a fraternal setting, Men and Masculinities, 10(5), 604-620.

Anderson, E. (2008b) “Being masculine is not about who you sleep with...”: Heterosexual athletes contesting masculinity and the one-time rule of homosexuality, Sex Roles(1-2), 104-115.

Anderson, E. (2008c) “I used to think women were weak”: Orthodox masculinity, gender segregation, and sport, Sociological Forum, 23(2), 257-280.

Anderson, E. (2009) Inclusive masculinity: The changing nature of masculinities (New York, Routledge).

Barnett, S., \& Thomson, K. (1996) Portraying sex: The limits of tolerance, in R. Jowell, J. Curtice, A. Park, L. Brook, \& K. Thomson (Eds.), British Social Attitudes, the $13^{\text {th }}$ Report (Aldershot, Hants: Social and Community Planning Research).

Britton, D. M., \& Williams, C. L. (1995) Don’t ask, don’t tell, don’t pursue: Military policy and the construction of heterosexual masculinity, Journal of homosexuality, 30(1), 1-21. 
Bryant, M. (2001) Gay male athletes and the role of the organized team and contact sports, Unpublished master’s thesis, Seattle Pacific University.

Burstyn, V. (1999) The rites of men: manhood politics and the culture of sport (Toronto, University of Toronto Press).

Burton-Nelson, M. (1994) The stronger women get, the more men love football: Sexism and the American culture of sports (New York, Harcourt Brace).

Connell, R.W. (1987) Gender and power (Stanford, CA, Stanford University Press).

Connell, R.W. (1995) Masculinities (Berkeley, University of California Press).

Coghlan, D. \& Brannick, D. (2000) Doing Action Research in your own Organization (London: Sage).

Davies, C. A. (1999) Reflexive ethnography: A guide to researching selves and others (London, Routledge).

Greenwood, D. J. \& Levin, M. (1998). Introduction to action research: Social research for social change. Thousand Oaks, CA: Sage.

Griffin, P. (1998) Strong women, deep closets: Lesbians and homophobia in sport (Champaign, IL, Human Kinetics).

Harris, J., \& Clayton, B. (2007) The first metrosexual rugby star: Rugby union, masculinity, and celebrity in contemporary Wales, Sociology of Sport Journal, 24, 145-164.

Hekma, G. (1998) As long as they don't make an issue of it...: Gay men and lesbians in organized sports in the Netherlands, Journal of Homosexuality, 35(1), [1-23.

Ibson, J. (2002) Picturing men: A century of male relationships in everyday American photography (Washington, Smithsonian Institution Press). 
Kehler, M. (2007) Hallway fears and high school friendships, Discourse: Studies in the Cultural Politics of Education, 28(2), 259-277.

Kimmel, M. S. (1994) Masculinity as homophobia: fear, shame and silence in the construction of gender identity, in: H. Brod \& M. Kaufman (Eds.), Theorizing masculinities (Thousand Oaks, CA, Sage), pp.119-141.

Lalor \& Rendle-Short (2007) ‘That’s so gay’: A contemporary use of gay in Australian English. Australian Journal of Linguistics 27(2), 147-173.

Loftus, J. (2001) America’s liberalization in attitudes toward homosexuality, 1973 to 1998, American Sociological Review, 66(5), 762-82.

May, R. A. B., \& Pattillo-McCoy, M. (2000). Do you see what I see? Examining a collaborative ethnography. Qualitative Inquiry 6(1): 65-87.

McCann, P.D.; Minichiello, V \& Plummer, D (2009) Is homophobia inevitable? Evidence that explores the constructed nature of homophobia, and the techniques through which men unlearn it, Journal of Sociology, 45 (2), 201-220. McNair, B. (2002). Striptease culture: The democratization of desire. London: Routledge.

McNiff, J. \& Whitehead, J. (2006). All you need to know about action research. London: Sage.

Messner, M.A. (1992), Power at play: sports and the problem of masculinity (Boston, Beacon Press).

Messner, M. A. \& Sabo, D. (1994) Sex, violence and power in sports (Freedom, CA, Crossing). 
Nylund, D. (2007) Beer, babes, and balls: Masculinity and sports talk radio (New York, State University of New York Press).

Oberhuber, F., \& Krzyzanowksi, M. (2008). Discourse analysis and ethnography. In R. Wodak \& M. Krzyzanowksi (Eds.), Qualitative discourse analysis in the social sciences, pp.182-203 (Basingstoke, UK: Palgrave Macmillan).

Pettigrew, T. F. (2008) Future directions for intergroup contact theory and research. International Journal of Intercultural Relations, 32, 187-199.

Pharr, S. (1997). Homophobia: A weapon of sexism. Berkeley, CA: Chardon Press.

Plummer, D. (1999) One of the boys: Masculinity, homophobia and modern manhood (New York, Haworth Press).

Price, M. \& Parker, A. (2003) Sport, sexuality and the gender order: Amateur rugby union, gay men, and social exclusion, Sociology of Sport Journal, 20(2), 108126.

Pronger, B. (1990) The arena of masculinity: Sports, homosexuality, and the meaning of sex (New York, St. Martin’s Press).

Reason, P. \& Bradbury, H. (2001). The SAGE handbook of action research. Participative inquiry and practice (1 $1^{\text {st }}$ Ed.). London: Sage.

Sabo, D. \& Runfola, R. (1980) Jock: Sports and male identity. Englewood Cliffs, N.J.: Prentice-Hall.

Southall, R.M., Nagel, M.S., Anderson, E.D., Polite, F.G., \& Southall, C. (2009) An investigation of male college athletes’ attitudes toward sexual-orientation. Journal of Issues in Intercollegiate Athletics, 2, 62-77. 
Spradley, J. P. (1970) You owe yourself a drunk: An ethnography of urban nomads, (Boston, MA, Little \& Brown).

Taulke-Johnson, R.A. (2008) Moving beyond homophobia, harassment and intolerance: Gay male university students? Alternate narratives, Discourse: Studies in the Cultural Politics of Education, 29(1), 121-

Weeks, J. (2007). The world we won. London: Routledge.

Whitson, D. (1990) Sport in the social construction of masculinity, in: M. Messner \& D. Sabo (Eds.) Sport, men, and the gender order: Critical feminist perspectives (Champaign, IL, Human Kinetics) pp.19-30.

Widmer, E. D., Treas, J., \& Newcomb, R. (1998) Attitudes towards nonmarital sex in 24 countries, Journal of Sex Research, 35(4), 349.

Wolf Wendel, L., Toma, D., \& Morphew, C. (2001) How much difference is too much difference? Perceptions of gay men and lesbians in intercollegiate athletics, Journal of College Student Development, 42(5), 465-479. 